\title{
Development of Loop-Mediated Isothermal Amplification (LAMP) Assay for Rapid Detection of Cannabis sativa
}

\author{
Masashi Kitamura, ${ }^{a, b}$ Masako Aragane, ${ }^{c}$ Kou Nakamura, ${ }^{c}$ Kazuhito Watanabe, ${ }^{d}$ and \\ Yohei Sasaki*,a \\ ${ }^{a}$ Laboratory of Molecular Pharmacognosy, Division of Pharmaceutical Sciences, Graduate School of Medical \\ Sciences, Kanazawa University; Kakuma-machi, Kanazawa, Ishikawa 920-1192, Japan: ${ }^{b}$ Forensic Science \\ Laboratory, Ishikawa Prefectural Police H.Q.; 1-1 Kuratsuki, Kanazawa, Ishikawa 920-8553, Japan: ${ }^{c}$ Medicinal \\ Plant Garden, Tokyo Metropolitan Institute of Public Health; 21-1 Nakajima-cho, Kodaira, Tokyo 187-0033, \\ Japan: and ${ }^{d}$ Faculty of Pharmaceutical Sciences, Hokuriku University; Ho-3 Kanagawa-machi, Kanazawa 920-1181, \\ Japan. \\ Received January 27, 2016; accepted April 14, 2016; advance publication released online April 27, 2016
}

\begin{abstract}
In many parts of the world, the possession and cultivation of Cannabis sativa $\mathrm{L}$. are restricted by law. As chemical or morphological analyses cannot identify the plant in some cases, a simple yet accurate DNA-based method for identifying $C$. sativa is desired. We have developed a loop-mediated isothermal amplification (LAMP) assay for the rapid identification of $C$. sativa. By optimizing the conditions for the LAMP reaction that targets a highly conserved region of tetrahydrocannabinolic acid (THCA) synthase gene, $C$. sativa was identified within $50 \mathrm{~min}$ at $60-66^{\circ} \mathrm{C}$. The detection limit was the same as or higher than that of conventional PCR. The LAMP assay detected all 21 specimens of $C$. sativa, showing high specificity. Using a simple protocol, the identification of $C$. sativa could be accomplished within $90 \mathrm{~min}$ from sample treatment to detection without use of special equipment. A rapid, sensitive, highly specific, and convenient method for detecting and identifying $C$. sativa has been developed and is applicable to forensic investigations and industrial quality control.
\end{abstract}

Key words Cannabis sativa; isothermal amplification; tetrahydrocannabinolic acid; loop-mediated isothermal amplification; marijuana; hemp

Cannabis sativa L. (Family Cannabaceae) has been cultivated for thousands of years for use as food, medicine, and fiber. ${ }^{1)}$ C. sativa seeds are a good source of nutrition because of their high quality protein and lipid. ${ }^{2)}$ Also called mashinin, the seeds are used as a laxative in Kanpo medicine. Its fiber is utilized in the manufacture of rope, paper, and fabric. However, despite these notable characteristics, the cultivation and possession of $C$. sativa are restricted by law in many parts of the world because $C$. sativa possesses strong psychoactive effects. ${ }^{3)} C$. sativa tops and leaves contain cannabinoids, which are the characteristic chemical compounds in $C$. sativa. More than 70 cannabinoids, including tetrahydrocannabinolic acid (THCA), have been isolated from $C$. sativa. ${ }^{4-6)}$ Tetrahydrocannabinol (THC), the decarboxylated form of THCA, is the primary cannabinoid responsible for the strong psychoactivite effects. ${ }^{1,7)}$

The identification of $C$. sativa species is crucial for forensic investigation and industrial quality control. C. sativa can be discriminated from other species by morphological analysis using cystolithic hairs on the leaves or chemical analyses using HPLC, liquid chromatography-mass spectrometry (LC-MS), or GC-MS. ${ }^{8-13)}$ However, it is difficult to distinguish $C$. sativa samples as they lack distinct morphological or chemical characteristics. In those cases, DNA analyses are used for species identification. It has been reported that DNAbased assays using PCR or real-time quantitative PCR are able to detect $C$. sativa, but those assays require long hours for DNA extraction and special equipment, such as a thermal cycler. $^{14-17)}$

Loop-mediated isothermal amplification (LAMP) is a nucle- otide acid amplification method that features high sensitivity, specificity, and rapidity under isothermal conditions. ${ }^{18)}$ LAMP requires a set of four primers to react with six distinct regions in the target. The reaction is accelerated by adding two loop primers and can be visually detected by the white turbidity that results from magnesium pyrophosphate accumulation during amplification. ${ }^{19,20)}$ It does not need any special devices or experienced technicians; thus, it is widely used for various purposes, such as detecting viruses and medicinal herbs. ${ }^{21-24)}$

One of the most species-specific genes in C. sativa is the THCA synthase gene that consists of a $1632 \mathrm{bp}$ open reading frame. THCA synthase gene was cloned and polymorphism analysis revealed that 63 nucleotide substitutions divided the species into two chemotypes: the THCA-rich type (drug type), such as marijuana, and the THCA-poor type (fiber type), such as hemp. ${ }^{25)}$ It has been suggested that 37 amino acid substitutions corresponding to the polymorphism determine the ability of THCA synthesis. ${ }^{25-27)}$ THCA synthase gene does not have high homology with any genes of other species. In this study, we have developed a novel LAMP assay for detecting C. sativa by targeting the conserved region of THCA synthase gene. This method is rapid, sensitive, highly specific, and convenient.

\section{MATERIALS AND METHODS}

Materials and DNA Extraction We used 20 specimens of C. sativa from the Medical Plant Garden, Tokyo Metropolitan Institute of Public Health, one specimen of $C$. sativa from Hokuriku University, which has been granted permission 
451 GCCGGAGCTACCCTTGGAGAAGTITATTATTGGATCAATGAGAGAATGA 500 451 GCCGGAGCTACCCTTGGAGAAGTTTATTATTGGATCAATGAGATGAATGA 500

F2

LF

501 GAATCTTAGTTTTCCTGGTGGGTATTGCCCTACTGTTGGCGTAGGTGGAC 550 501 GAATTTTAGTTTTCCTGGTGGGTATTGCCCTACTGTTGGGGTAGGTGGAC 550

F1

B1

551 ÄCTTTAGT $\stackrel{\leftrightarrow}{\rightleftarrows}$ 551 ACTTTAGTGGAGGAGGCTATGGAGCATTGATGCGAAATTATGGCCTTGCG 600

B2

601 GCTGATAATATTATTGATGCACACTTAGTCAATGTTGATGGAAAAGTTCT 650 601 GCTGATAATATCATTGATGCACACTTAGTCAATGTTGATGGAAAAGTTCT 650

\section{B3}

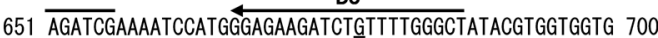
651 AGATCGAAAATCCATGGGAGAAGATCTATTTTGGGCTATACGTGGTGGAG 700

\begin{tabular}{|c|c|c|}
\hline Primer & Sequence $\left(5^{\prime}-3^{\prime}\right)$ & Nucleotide position $^{*}$ \\
\hline F3 & TGGATCAATGAGATGAATGAGA & $481-502$ \\
\hline B3 & AGCCCAAAATAGATCTTCTCC & $687-667$ \\
\hline FIP $\left(F 1 c^{* *}-F 2\right)$ & $\begin{array}{l}\text { CAATGCTCCATAGCCTCCTCC-T } \\
\text { GGTGGGTATTGCCCTAC }\end{array}$ & $(579-559)(516-533)$ \\
\hline $\mathrm{BIP}\left(\mathrm{B} 1-\mathrm{B} 2 \mathrm{c}^{* *}\right)$ & $\begin{array}{l}\text { ATGCGAAATTATGGCCTTGCG-C } \\
\text { GATCTAGAACTTTTCCATCAAC }\end{array}$ & $(580-600)(656-634)$ \\
\hline LF & TGTCCACCTACGCCAACA & $551-534$ \\
\hline
\end{tabular}

Fig. 1. Primer Design for LAMP

Nucleotide sequence of THCA synthase gene. The upper array is the drug-type sequence (accession No. AB212834) and the lower array is the fiber-type sequence (accession No. AB212830). The sequences of the primer binding sites are indicated by arrows. Nucleotide differences in the used primer sequences are underlined.

to study C. sativa by Ishikawa Prefecture, and seven species, namely, Humulus lupulus, Humulus japonicus, Cudrania tricuspidata, Paeonia lactiflora, Angelica acutiloba, Matricaria recutita, and Glycyrrhiza glabra, from the Medicinal Plant Garden, Kanazawa University. The specimens of $C$. sativa had been cultivated in each institute, but the origin of genetic background is unknown. All specimens were deposited in the herbarium of Kanazawa University and the Forensic Science Laboratory in Ishikawa Prefecture. Total genomic DNA was extracted from each dried leaf using a DNeasy Plant Mini Kit (Qiagen, Germany) according to the manufacturer's instructions. Each DNA concentration was measured at $260 \mathrm{~nm}$ and adjusted to the final concentration of $5 \mathrm{ng} / \mu \mathrm{L}$ with sterile water for use.

Primer Design LAMP primers were designed on the basis of fiber-type THCA synthase gene (DDBJ/EMBL/ GenBank database accession No. AB212830). Regarding polymorphism, THCA synthase gene is one of the most analyzed genes in C. sativa. Drug-type (accession No. AB212834) and fiber-type (accession No. AB212830) THCA synthase genes were aligned and the conserved regions were selected to design LAMP primers using PrimerExplorer V3 and V4 (https:// primerexplorer.jp). Two outer primers, one forward primer (FIP), and one backward inner primer (BIP) were designed for the LAMP reaction. A loop primer (LF) was designed to accelerate the reaction. The primer sequences are indicated in Fig. 1 .

LAMP Reaction and Optimization of Reaction Conditions The LAMP reaction was performed with a Loopamp DNA Amplification Kit (Eiken Chemical Co., Ltd., Tokyo, Japan) according to the manufacturer's protocol with minor modification. Briefly, a $25 \mu \mathrm{L}$ mixture containing $12.5 \mu \mathrm{L}$ of
$2 \times$ Reaction mix, 8 units of Bst DNA polymerase, $0.5 \mu \mathrm{L}$ of Loopamp Fluorescent Detection Reagent (Eiken Chemical Co., Ltd.), $0.2 \mu \mathrm{M}$ each of F3 and B3 primers, $1.6 \mu \mathrm{M}$ each of FIP and BIP primers, $0.8 \mu \mathrm{M}$ of LF primer, and $1 \mu \mathrm{L}$ of each genomic DNA as template was incubated at $60,63,66$, and $69^{\circ} \mathrm{C}$ for 90 or $150 \mathrm{~min}$ and then heated at $80^{\circ} \mathrm{C}$ for $5 \mathrm{~min}$ by a Smart Cycler (Cepheid). The fluorescence produced when calcein formed a chelate with magnesium ion was observed at wavelengths between 565 and $590 \mathrm{~nm}$. The baseline and the threshold cycle $(\mathrm{Ct})$ were automatically determined by Smart Cycler. Ct was converted into the initial rise time.

Sensitivity of LAMP Assay LAMP assay and conventional PCR were performed with serial 10-fold dilutions of genomic DNA of Afghani special from 10 to $0.001 \mathrm{ng}$ as template. Conventional PCR was conducted in a final volume of $25 \mu \mathrm{L}$ containing $1 \times$ PCR buffer (TaKaRa, Japan), $0.2 \mathrm{~mm}$ of each deoxyribonucleotide triphosphate (dNTP) (TaKaRa), $0.5 \mu \mathrm{M}$ each of F3 and B3 primers, 0.625 unit of Ex Taq DNA polymerase (TaKaRa), and $1 \mu \mathrm{L}$ of each genomic DNA. PCR conditions were as follows: initial denaturation at $94^{\circ} \mathrm{C}$ for $5 \mathrm{~min}$, followed by 35 cycles of denaturation at $94^{\circ} \mathrm{C}$ for $30 \mathrm{~s}$, annealing at $55^{\circ} \mathrm{C}$ for $30 \mathrm{~s}$, and extension at $72^{\circ} \mathrm{C}$ for $30 \mathrm{~s}$, with a final extension at $72^{\circ} \mathrm{C}$ for $5 \mathrm{~min}$, followed by a $4^{\circ} \mathrm{C}$ hold. The PCR products were electrophoresed on $2 \%$ agarose gels with ethidium bromide staining.

Specificity of LAMP Assay LAMP specificity was tested with the DNA samples extracted from the 21 specimens of $C$. sativa as positive control and from seven species, including $H$. lupulus and $H$. japonicus, which are closely related to $C$. sativa, as negative control.

Sequencing Analysis and Cloning THCA synthase gene was amplified by PCR using forward primer $\left(5^{\prime} \rightarrow 3^{\prime}\right.$; GCGGAT CCATGAATT GCTCAGCAT TTTCCTTTT) and reverse primer $\left(5^{\prime} \rightarrow 3^{\prime}\right.$; GCC TGC AGT CTA TTT AAA GAT AAT TAA TGA TGA TGCGGTGG) of reported oligonucleotide primers with minor modification. ${ }^{25)}$ The PCR products were treated with ExoSAP-IT (Affymetrix) to remove unconsumed dNTPs and excess primers. The purified PCR products were sequenced with a BigDye Terminator v1.1 Cycle Sequencing Kit (Applied Biosystems) and a 3130xl Genetic Analyzer (Applied Biosystems) according to the manufacturer's instructions.

Two types of THCA synthase genes were cloned as follows. PCR products of THCA synthase gene obtained from $C$. sativa (Big Bud) were digested with Bam $\mathrm{HI}$ and Pst I, ligated into pBluescript vector, and transformed in E. coli. Sequence analysis showed that each clone of THCA synthase gene had the sequence of drug type (accession No. LC120319) or fiber type (accession No. LC120320) in the LAMP targeting region and these sequences were registered by authors. Constructed plasmids were diluted to $0.01 \mathrm{fmol} / \mu \mathrm{L}$ with sterile water for use.

Simple Sample Preparation for LAMP Assay A piece of dried leaf (approximately $3 \mathrm{mg}$ ) was added to $100 \mu \mathrm{L}$ of lysis buffer consisting of phosphate buffered saline (PBS) with a final concentration of $5 \%$ Tween 20 and $1 \mu \mathrm{g} / \mu \mathrm{L}$ proteinase $\mathrm{K}$ (Qiagen). The lysis sample was heated at $56^{\circ} \mathrm{C}$ for $5 \mathrm{~min}$ and then at $95^{\circ} \mathrm{C}$ for $5 \mathrm{~min}$, and centrifuged. As DNA template, $1 \mu \mathrm{L}$ of the supernatant was used for the LAMP assay. 
A Detection by fluorescence

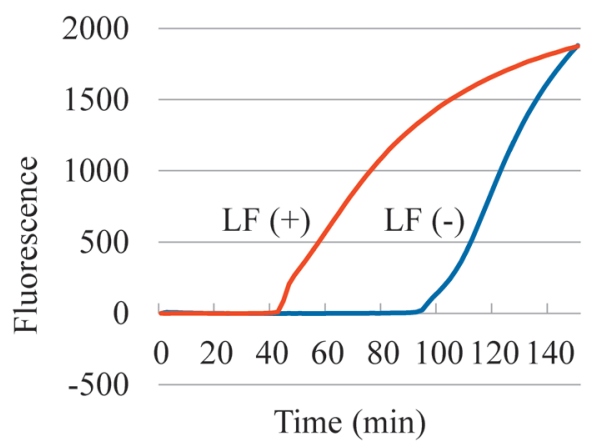

B Detection by electrophoresis

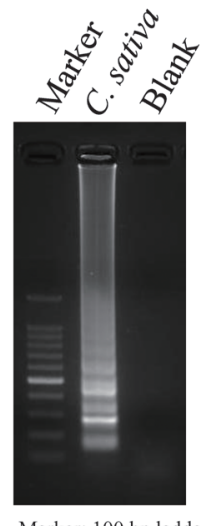

Marker: 100 bp ladder
C Detection under natural light

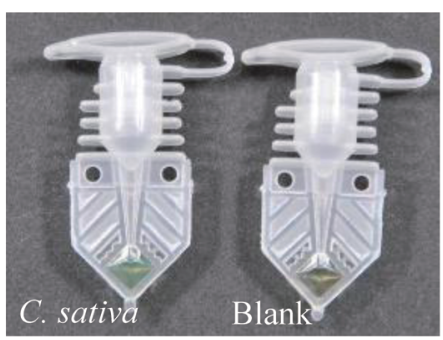

D Detection under ultraviolet irradiation

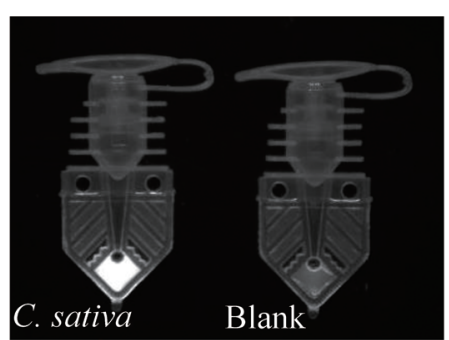

Fig. 2. LAMP Reaction Using a Set of Primers for Detecting C. sativa

LAMP reactions were monitored by Smart Cycler (A). Fluorescence signal ( $y$-axis) was observed on a channel that detects wavelengths between 565 and 590 nm in real time. LAMP reactions with a loop primer $(\mathrm{LF}(+))$ or without a loop primer (LF $(-))$ were performed. Positive reactions were visualized by agarose gel electrophoresis $(\mathrm{B})$, under natural light (C), and by UV irradiation (D).
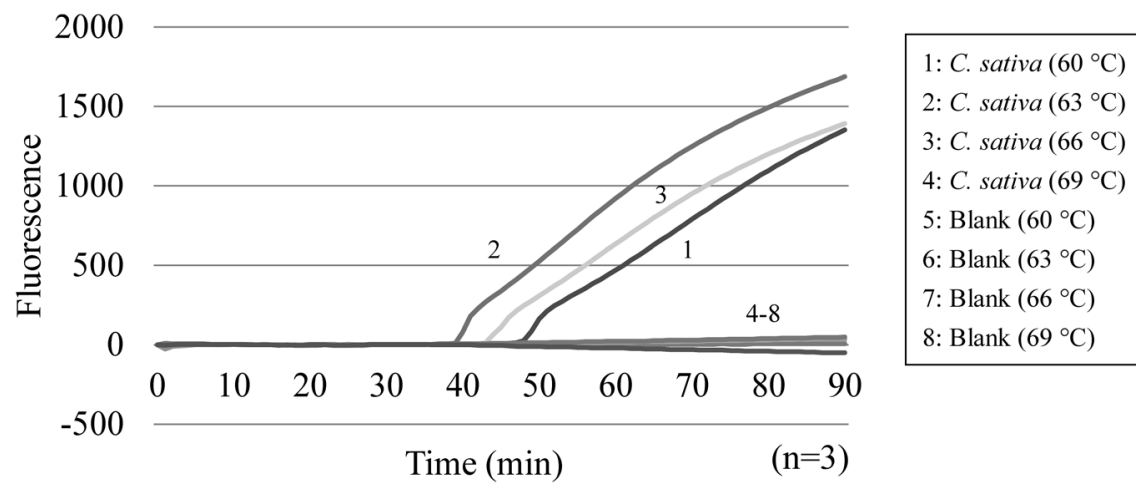

Fig. 3. Optimization of LAMP Reaction Temperature

The LAMP assay was conducted at $60,63,66$, and $69^{\circ} \mathrm{C}$. Amplification was detected at 60,63 , and $66^{\circ} \mathrm{C}$, but not at $69^{\circ} \mathrm{C}$. Non-specific amplification did not occur at any temperature.

\section{RESULTS AND DISCUSSION}

Design of LAMP Primers We aligned THCA synthase gene and selected the conserved regions in the THCA synthase gene for designing LAMP primers (Fig. 1). LAMP primers consist of two outer primers (F3, B3), two inner primers (FIP, BIP), and a loop primer (LF). The forward inner primer (FIP) consists of F1c and F2, and the backward inner primer (BIP) consists of B1 and B2c. F1c and B2c are complementary sequences of $\mathrm{F} 1$ and $\mathrm{B} 1$, respectively. Each binding site of F3 and B3 contains a single nucleotide polymorphism between the drug-type and fiber-type THCA synthase genes. As each single nucleotide polymorphism is located in the middle of the primer sequence, it was probable that the mutation did not influence the LAMP reaction. In addition, to reduce the reaction time, an LF primer was designed.

Optimization of LAMP Reaction Conditions The LAMP assay using a set of primers for detecting $C$. sativa was performed. The fluorescence derived from the calceinmagnesium chelate was measured at wavelengths between 565 and $590 \mathrm{~nm}$ using Smart Cycler $^{28)}$ (Fig. 2A). With C. sativa DNA as template, the initial rise time was $92.9 \pm 2.6 \mathrm{~min}$ without LF. When LF was added, the initial rise time was $39.3 \pm 1.9 \mathrm{~min}$, more than $50 \mathrm{~min}$ shorter than the time without 


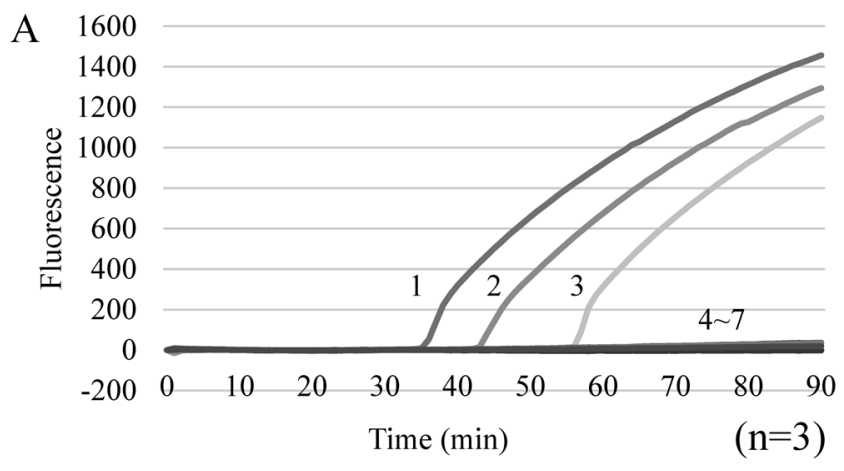

B

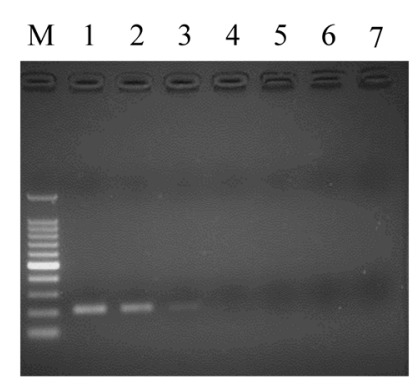

\begin{tabular}{|l|}
\hline 1: $10 \mathrm{ng}$ \\
2: $1 \mathrm{ng}$ \\
3: $0.1 \mathrm{ng}$ \\
4: $0.01 \mathrm{ng}$ \\
5: $0.001 \mathrm{ng}$ \\
6: H. lupulus (25 ng) \\
7: Blank \\
\hline
\end{tabular}

M: 100 bp ladder

Fig. 4. Comparison of Sensitivity between LAMP and Conventional PCR

Serial 10 -fold dilutions of genomic DNA (10 to $0.001 \mathrm{ng}$ ) were used as DNA template for the LAMP assay (A) and PCR (B). Sensitivity of the LAMP assay was the same as or higher than that of conventional PCR.

LF. Moreover, agarose gel electrophoresis revealed a typical ladder-like pattern in a positive sample (Fig. 2B). As LAMP assays have 100 to 1000 -fold amplification efficiency compared with PCR in general, cross-contamination caused by opening tubes after LAMP reaction poses a serious problem. To avoid cross-contamination, the electrophoresis of LAMP products was performed in a physically separated room. The amplification product was easily observed as green fluorescence under natural light (Fig. 2C). Under ultraviolet irradiation, it was also detected as the fluorescence of the calceinmagnesium chelate (Fig. 2D).

To determine the optimum reaction temperature, the LAMP assay was conducted at $60,63,66$, and $69^{\circ} \mathrm{C}$ (Fig. 3). The amplifications occurred at $44.6 \pm 2.9,39.3 \pm 1.9$, and $44.3 \pm 4.3 \mathrm{~min}$ at 60,63 , and $66^{\circ} \mathrm{C}$, respectively, but not at $69^{\circ} \mathrm{C}$. There was no non-specific amplification occurring at $90 \mathrm{~min}$ at any temperature. Because the initial rise time at $63^{\circ} \mathrm{C}$ was shorter than those at 60 and $66^{\circ} \mathrm{C}$, we determined that the optimum temperature for the assay was $63^{\circ} \mathrm{C}$ whereas the amplification could be detected at a broad range of temperatures between 60 and $66^{\circ} \mathrm{C}$ within $50 \mathrm{~min}$. These results indicated that the LAMP assay does not require a precise temperature control system, such as a thermal cycler, and a simple device, such as a water bath or a heating block, is sufficient for the assay.

Sensitivity of LAMP Assay To evaluate the sensitivity, serial 10-fold dilutions of genomic DNA (10 to $0.001 \mathrm{ng}$ ) were used as DNA template for the LAMP assay and PCR. The fluorescence intensity was enhanced with the DNA template of 10,1 , and $0.1 \mathrm{ng}$, and the initial rise time was $37.8 \pm 2.0$, $41.8 \pm 1.4$, and $52.2 \pm 7.1 \mathrm{~min}$, respectively. No amplification was observed with the $0.01 \mathrm{ng}$ DNA template (Fig. 4A). For
Table 1. List of Cannabis sativa and Other Species as Negative Controls in This Study and Results of Specificity by LAMP Reaction Using the Primer Set for C. sativa

\begin{tabular}{|c|c|c|c|}
\hline No. & Product name (Species) & $\begin{array}{c}\text { THCA synthase } \\
\text { gene type }\end{array}$ & Initial rise time \\
\hline 1 & Afghani special & Drug & $39.3 \pm 1.9$ \\
\hline 2 & Bahia Black Head & Drug & $37.2 \pm 0.6$ \\
\hline 3 & Big Bud & Drug/Fiber & $32.5 \pm 0.4$ \\
\hline 4 & CAL. ORANGE & Drug/Fiber & $31.8 \pm 0.4$ \\
\hline 5 & Crystal Paradise & Drug & $38.6 \pm 0.7$ \\
\hline 6 & Durban Poison & Drug/Fiber & $33.6 \pm 0.4$ \\
\hline 7 & Early Bud & Drug & $37.4 \pm 0.5$ \\
\hline 8 & Haze Special & Drug & $38.8 \pm 1.2$ \\
\hline 9 & ISIS & Drug & $37.6 \pm 1.1$ \\
\hline 10 & Leda Uno & Drug & $39.5 \pm 0.4$ \\
\hline 11 & Mango & Drug & $35.4 \pm 0.2$ \\
\hline 12 & Northern Light & Drug/Fiber & $34.2 \pm 0.7$ \\
\hline 13 & Northern Light Special & Drug & $37.4 \pm 0.7$ \\
\hline 14 & PURPLE & Drug/Fiber & $31.5 \pm 0.7$ \\
\hline 15 & PURPLE STAR & Drug/Fiber & $34.0 \pm 0.2$ \\
\hline 16 & SACRA FRASCA & Drug & $38.3 \pm 0.5$ \\
\hline 17 & SHAMAN & Drug/Fiber & $33.2 \pm 0.6$ \\
\hline 18 & SKUNK PASSION & Drug & $37.4 \pm 0.7$ \\
\hline 19 & TWILIGHT & Drug & $37.7 \pm 0.9$ \\
\hline 20 & VOODOO & Drug & $34.2 \pm 0.4$ \\
\hline 21 & Unknown & Drug/Fiber & $34.4 \pm 0.5$ \\
\hline N1 & (Humulus lupulus) & - & Not detected \\
\hline $\mathrm{N} 2$ & (Humulus japonicus) & - & Not detected \\
\hline N3 & (Cudrania tricuspidata) & - & Not detected \\
\hline N4 & (Paeonia lactiflora) & - & Not detected \\
\hline N5 & (Angelica acutiloba) & - & Not detected \\
\hline N6 & (Matricaria recutita) & - & Not detected \\
\hline N7 & (Glycyrrhiza glabra L.) & - & Not detected \\
\hline
\end{tabular}

comparison with conventional PCR, PCR using F3 and B3 was carried out. By agarose gel electrophoresis, amplification of THCA synthase gene was detected from 0.1 to $10 \mathrm{ng}$, but the PCR product of the $0.1 \mathrm{ng}$ DNA template was not clearly observed (Fig. 4B). These results demonstrated that the sensitivity of the LAMP assay was the same as or higher than that of PCR and the minimum amount of DNA template necessary for the LAMP assay was $0.1 \mathrm{ng}$. Furthermore, our LAMP assay showed higher sensitivity than the previously reported assay that required $5 \mathrm{ng}$ of DNA template to discriminate species for various purposes. $\left.{ }^{15}\right)$

Specificity of LAMP Assay The specificity of the LAMP assay for 21 specimens of $C$. sativa and seven other species, including $H$. lupulus and $H$. japonicus, was tested. All specimens of Cannabis spp. were detected in the LAMP reaction within $45 \mathrm{~min}$ (Table 1). No other species, including closely related species, such as $H$. lupulus and $H$. japonicus, were amplified within $90 \mathrm{~min}$. Regarding the reaction time, the initial rise times of the 21 specimens varied from $31.5 \pm 0.7 \mathrm{~min}$ (No. 14; PURPLE) to $39.5 \pm 0.4 \mathrm{~min}$ (No. 10; Leda Uno). To investigate reaction time differences among the specimens, we performed sequence analyses of the LAMP targeting region in THCA synthase gene. The sequence analyses revealed that 13 specimens had only the drug-type sequence and 8 specimens had both drug-type and fiber-type sequences. The average initial rise time of the group having both drug-type and fibertype THCA synthase genes was $33.2 \pm 1.1 \mathrm{~min}$, shorter than 
that of the group having only drug-type THCA synthase gene ( $37.8 \pm 1.8 \mathrm{~min})$. Because the LAMP primers were designed on the basis of the fiber-type sequence, it is probable that misannealing of the drug-type THCA synthase gene increased the reaction time. However, these slight differences in the reaction time did not pose any problems in $C$. sativa detection because several factors, such as DNA concentration, DNA quality, reagent lot, and devices, could influence the reaction time. In this study, there were no specimens having only fiber-type THCA synthase gene. To test the LAMP reactivity for the fiber-type THCA synthase gene, we conducted the LAMP assay using the cloned THCA synthase gene as template. As shown in Fig. 5, the LAMP assay was able to detect each type of THCA synthase gene. The initial rise times of drug- and fiber-

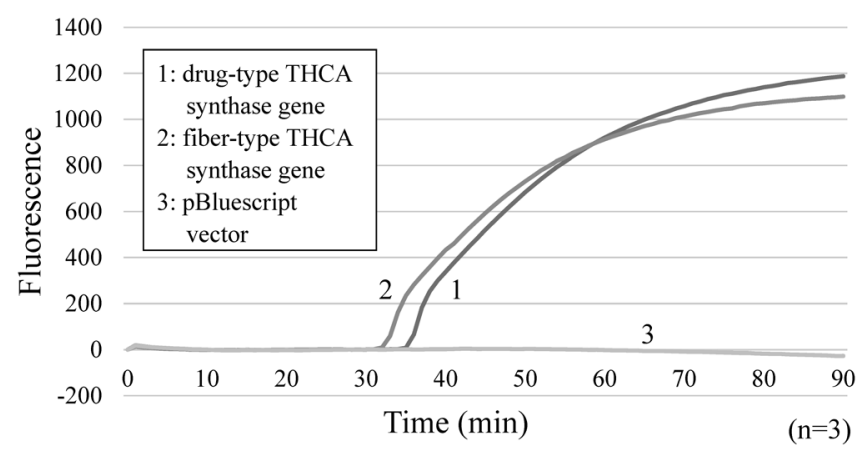

Fig. 5. Specificity for THCA Synthase Gene

The reactivity of constructed plasmid containing drug-type THCA synthase gene (accession No. LC120319) or fiber-type THCA synthase genes (accession No. LC120320) was tested by LAMP assay. Amplifications were noted with both types of DNA templates, whereas no amplification was noted with empty vector (pBluescript vector). type THCA synthase genes when $0.01 \mathrm{fmol}$ plasmid DNA was used were $33.8 \pm 1.3$ and $31.0 \pm 1.4 \mathrm{~min}$, respectively. These results indicated that the LAMP primer set is highly specific to both gene types. Thus, $C$. sativa having only fiber-type THCA synthase gene can be detected with this method. Accordingly, the results showed that this method has high species specificity for C. sativa.

Simple Sample Preparation for LAMP Assay Because some inhibitory compounds exist in plant tissues, such as polysaccharides or secondary metabolites, direct amplification of unpurified DNA seems to be difficult for enzymatic reactions in general. However, as Bst polymerase, which is used in the LAMP assay, is robust to the inhibitors, some protocols that require no DNA extraction have been reported. ${ }^{29)}$ To simplify the DNA extraction procedure, a simple method for sample preparation was evaluated for the LAMP assay. ${ }^{30,31)}$ Supernatants of heat-treated samples following proteinase treatment were used as DNA template. As indicated in Fig. 6, the purified DNA template and the supernatant of $C$. sativa leaf (No. 18; SKUNK PASSION) showed fluorescence amplification at $37.4 \pm 0.7$ and $45.8 \pm 2.2 \mathrm{~min}$, respectively, whereas the supernatants of leaves of the other species showed no amplification. The results indicate that identifying $C$. sativa leaf can be completed within $90 \mathrm{~min}$ from sample preparation to detection.

\section{CONCLUSION}

We have developed a LAMP assay to identify $C$. sativa using LAMP primers with conserved THCA synthase gene. The LAMP assay is convenient and its sensitivity is the same

A

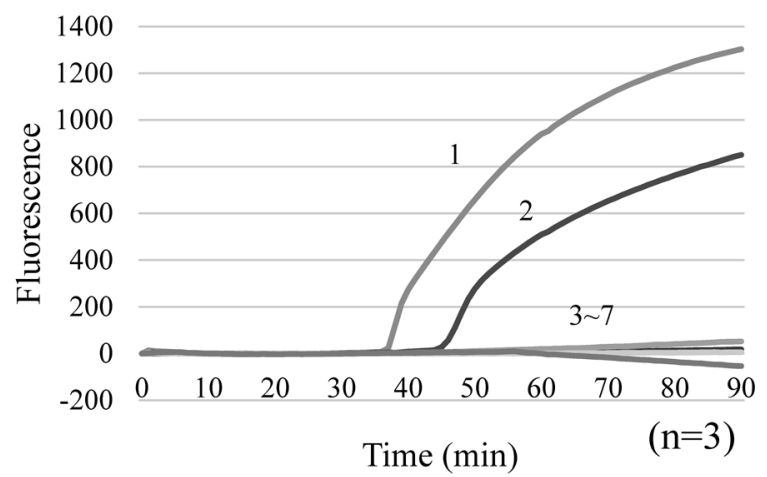

B

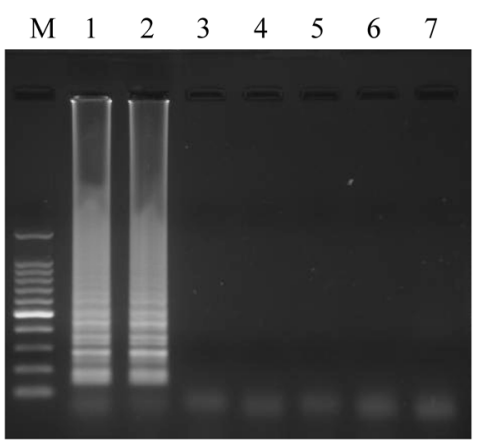
1: C. sativa (DNA)
2: C. sativa (Leaf)
3: Humulus lupulus (Leaf)
4: Humulus japonicus (Leaf)
5: Cudrania tricuspidata (Leaf)
6: Angelica acutiloba (Leaf)
7: Blank

M: 100 bp ladder

Fig. 6. Simple Sample Preparation for LAMP Assay

Leaf samples were treated with proteinase, heated, and centrifuged. The supernatant of $C$. sativa leaf showed fluorescence amplification whereas the supernatants of leaves of other species showed no amplification (A). A typical LAMP product (ladder-like pattern) was detected from C. sativa leaf by agarose gel electrophoresis (B). 
as or higher than those of conventional DNA-based methods. The LAMP reaction can be performed under isothermal conditions at $60-66^{\circ} \mathrm{C}$ without the need for special equipment. Moreover, the simple procedure using unpurified DNA template can be accomplished within $90 \mathrm{~min}$ from pretreatment to detection. These characteristics indicate that the LAMP assay is suitable for on-site detection or less well-equipped laboratories. This rapid, sensitive, highly specific, and convenient method for detecting and identifying $C$. sativa may be used as a reliable tool for forensic investigation and industrial quality control.

Acknowledgments This research was partly supported by a Grant from the Research Foundation for Safe Society. We thank our colleagues for the support extended in the course of this study.

Conflict of Interest The authors declare no conflict of interest.

\section{REFERENCES}

1) Grotenhermen F. Pharmacokinetics and pharmacodynamics of cannabinoids. Clin. Pharmacokinet., 42, 327-360 (2003).

2) House JD, Neufeld J, Leson G. Evaluating the quality of protein from hemp seed (Cannabis sativa L.) products through the use of the protein digestibility-corrected amino acid score method. $J$. Agric. Food Chem., 58, 11801-11807 (2010).

3) Hillig KW, Mahlberg PG. A chemotaxonomic analysis of cannabinoid variation in Cannabis (Cannabaceae). Am. J. Bot., 91, 966-975 (2004).

4) Ahmed SA, Ross SA, Slade D, Radwan MM, Zulfiqar F, Matsumoto RR, Xu YT, Viard E, Speth RC, Karamyan VT, ElSohly MA. Cannabinoid ester constituents from high-potency Cannabis sativa. $J$. Nat. Prod., 71, 536-542 (2008).

5) Elsohly MA, Slade D. Chemical constituents of marijuana: the complex mixture of natural cannabinoids. Life Sci., 78, 539-548 (2005).

6) Radwan MM, Elsohly MA, Slade D, Ahmed SA, Khan IA, Ross SA. Biologically active cannabinoids from high-potency Cannabis sativa. J. Nat. Prod., 72, 906-911 (2009).

7) de Meijer EP, Bagatta M, Carboni A, Crucitti P, Moliterni VM, Ranalli P, Mandolino G. The inheritance of chemical phenotype in Cannabis sativa L. Genetics, 163, 335-346 (2003).

8) Aizpurua-Olaizola O, Omar J, Navarro P, Olivares M, Etxebarria $\mathrm{N}$, Usobiaga A. Identification and quantification of cannabinoids in Cannabis sativa L. plants by high performance liquid chromatography-mass spectrometry. Anal. Bioanal. Chem., 406, 7549-7560 (2014).

9) Grauwiler SB, Scholer A, Drewe J. Development of a LC/MS/MS method for the analysis of cannabinoids in human EDTA-plasma and urine after small doses of Cannabis sativa extracts. J. Chromatogr. B Analyt. Technol. Biomed. Life Sci., 850, 515-522 (2007).

10) Debruyne D, Albessard F, Bigot MC, Moulin M. Comparison of three advanced chromatographic techniques for Cannabis identification. Bull. Narc., 46, 109-121 (1994).

11) Omar J, Olivares M, Alzaga M, Etxebarria N. Optimisation and characterisation of marihuana extracts obtained by supercritical fluid extraction and focused ultrasound extraction and retention time locking GC-MS. J. Sep. Sci., 36, 1397-1404 (2013).

12) Mitosinka GT, Thornton JI, Hayes TL. The examination of cystolithic hairs of Cannabis and other plants by means of the scanning electron microscope. J. Forensic Sci. Soc., 12, 521-529 (1972).

13) Yoshimatsu K, Kitazawa T, Kawano N, Iida O, Kawahara N. Char- acteristics of Cannabis sativa L.: seed morphology, germination and growth characteristics, and distinction from Hibiscus cannabinus L. Yakugaku Zasshi, 130, 237-246 (2010).

14) Linacre A, Thorpe J. Detection and identification of Cannabis by DNA. Forensic Sci. Int., 91, 71-76 (1998).

15) Tsai LC, Hsieh HM, Huang LH, Wang JC, Linacre A, Lee JC. Cannabis seed identification by chloroplast and nuclear DNA. Forensic Sci. Int., 158, 250-251 (2006).

16) Siniscalco Gigliano G. Preliminary data on the usefulness of internal transcribed spacer I (ITS1) sequence in Cannabis sativa L. identification. J. Forensic Sci., 44, 475-477 (1999).

17) Johnson CE, Premasuthan A, Satkoski Trask J, Kanthaswamy S. Species identification of Cannabis sativa using real-time quantitative PCR (qPCR). J. Forensic Sci., 58, 486-490 (2013).

18) Notomi $T$, Okayama $H$, Masubuchi $H$, Yonekawa $T$, Watanabe $K$, Amino N, Hase T. Loop-mediated isothermal amplification of DNA. Nucleic Acids Res., 28, 63e (2000).

19) Nagamine K, Hase T, Notomi T. Accelerated reaction by loop-mediated isothermal amplification using loop primers. Mol. Cell. Probes, 16, 223-229 (2002)

20) Mori Y, Nagamine K, Tomita N, Notomi T. Detection of loopmediated isothermal amplification reaction by turbidity derived from magnesium pyrophosphate formation. Biochem. Biophys. Res. Commun., 289, 150-154 (2001).

21) Kurosaki Y, Takada A, Ebihara H, Grolla A, Kamo N, Feldmann H, Kawaoka Y, Yasuda J. Rapid and simple detection of Ebola virus by reverse transcription-loop-mediated isothermal amplification. $J$. Virol. Methods, 141, 78-83 (2007).

22) Sasaki Y, Nagumo S. Rapid identification of Curcuma longa and $C$. aromatica by LAMP. Biol. Pharm. Bull., 30, 2229-2230 (2007).

23) Sasaki Y, Komatsu K, Nagumo S. Rapid detection of Panax ginseng by loop-mediated isothermal amplification and its application to authentication of Ginseng. Biol. Pharm. Bull., 31, 1806-1808 (2008).

24) Sasaki Y, Fujimoto T, Aragane M, Yasuda I, Nagumo S. Rapid and sensitive detection of Lophophora williamsii by loop-mediated isothermal amplification. Biol. Pharm. Bull., 32, 887-891 (2009).

25) Kojoma M, Seki H, Yoshida S, Muranaka T. DNA polymorphisms in the tetrahydrocannabinolic acid (THCA) synthase gene in "drugtype" and "fiber-type" Cannabis sativa L. Forensic Sci. Int., 159, 132-140 (2006)

26) Sirikantaramas S, Morimoto S, Shoyama Y, Ishikawa Y, Wada Y, Shoyama Y, Taura F. The gene controlling marijuana psychoactivity: molecular cloning and heterologous expression of Deltal-tetrahydrocannabinolic acid synthase from Cannabis sativa L. J. Biol. Chem., 279, 39767-39774 (2004).

27) Rotherham D, Harbison SA. Differentiation of drug and non-drug Cannabis using a single nucleotide polymorphism (SNP) assay. Forensic Sci. Int., 207, 193-197 (2011).

28) Mu Y, Zeng J, Chen Q, Liu J, Wang L, Yao F, Cui M, He Z, Zhang C, Xiao M, Lan K. New method for the visual detection of human respiratory syncytial virus using reverse transcription loop-mediated amplification. J. Virol. Methods, 206, 84-88 (2014).

29) Fukuta S, Kato S, Yoshida K, Mizukami Y, Ishida A, Ueda J, Kanbe M, Ishimoto Y. Detection of tomato yellow leaf curl virus by loop-mediated isothermal amplification reaction. J. Virol. Methods, 112, 35-40 (2003).

30) Kogovšek P, Hodgetts J, Hall J, Prezelj N, Nikolić P, Mehle N, Lenarčič R, Rotter A, Dickinson M, Boonham N, Dermastia M, Ravnikar M. LAMP assay and rapid sample preparation method for on-site detection of flavescence dorée phytoplasma in grapevine. Plant Pathol., 64, 286-296 (2015).

31) Fan F, Du P, Kan B, Yan M. The development and evaluation of a loop-mediated isothermal amplification method for the rapid detection of Salmonella enterica serovar. Typhi. PLoS ONE, 10, e0124507 (2015). 